\title{
Effectiveness of Instructional Electronic Games in Acquisition of Geometry Concepts Among Kindergarten Children
}

\author{
Reham Almohtadi $^{1} \quad$ Intisar Turki Aldarabah $^{2} \quad$ Mustafa Jwaifell $^{3 *}$ \\ Faculty of Education, Al-Hussein Bin Talal University, PO box 20, Postal code 71111, Ma'an, Jordan. \\ 3. https://orcid.org/0000-0002-7279-7253
}

\begin{abstract}
The study aimed to examine the effectiveness of using instructional electronic games in developing geometry concepts among kindergarten children. To achieve the study objective, the semi-experimental method was used. The study population consisted of all kindergarten students at the Pink Bird Nursery in Petra city. Sixty children were divided into two groups: the experimental group consisted of (30) children who were taught by using an instructional electronic game, and the control group consisted of (30) children who were taught by using the traditional way. Results of the study indicated that there are statistical differences in favor of using instructional electronic games in developing geometry concepts among kindergarten children.
\end{abstract}

Keywords: Instructional electronic games, Geometry, Kindergarten children

DOI: $10.7176 / \mathrm{RHSS} / 9-12-19$

Publication date:June $30^{\text {th }} 2019$

\section{Introduction}

The kindergarten stage is important for preparing to school. It provides a solid base of experiences and information that are important for children, which helps them to learn better in later stages and motivates them to learn by providing opportunities that develop their different skills, curiosity and self-esteem.

Children's concept of play has changed significantly as a result of the rapid changes witnessed by the world. Video games are an inevitable result of the information leap that occupied our lives in all its details. Thus, the children's attention has turned to electronic and video games, which succeeded in attracting them; males and females since their age of three (Shahrori \& Rimawi, 2011).

As a result of the widespread use of electronic games on one hand, and the fear of the consequences that might result from wasting the child's time in vain on the other hand, educators believed in the need to implement these games within the learning and teaching process, especially that one of the first uses of computers in the field of education is presented as a computer-assisted instruction (Pesso, 2002).

Dempsey et al. (2002) defines instructional games as an environment that provides an opportunity for learning through play, offering a variety of directive activities in which one or more players can be involved, by providing a virtual environment governed by disciplines, rules and constraints that combine competition, motivation and learning.

If technological development has invaded all areas of life to improve and develop it, it has clearly influenced the form of instructional games and its advantages. Otiefy \& Elmligy (2014) stated that instructional electronic games are important source for child education, through which the child can discover and enrich his imagination. Also, the child becomes more active in front of electronic games, easier to engage in society, and learns scientific thinking, which is having a problem and then working to solve it.

Several researches, such as the study of July (2001), confirm the effectiveness of employing teaching strategies or computer programs that are based on the principles of constructivism and active learning in providing students with mathematical concepts in general and geometry in particular. Constructivism is a contemporary educational trend that calls for the necessity of basing mathematics teaching on methods and strategies constructed on the learner's activity, his positive role in the learning situation, and his acquisition of the various learning domains of mathematics (Hamada, 2005).

Concepts, according to Jouda (2007), are the threads that make up the fabric of science, and the basis of mathematics epistemology. It helps the learner remember what he has learned, increases the ability to deeply understand the nature of science and helps to raise the level of thinking. It is also essential for transferring information and acquired skills from one situation to another, and constitutes the infrastructure for any discipline.

Therefore, if the process of forming the mathematical concept is not done correctly and firmly, the information acquired in the subsequent stages of education remains confused because it loses the solid ground on which it depends (Altaee \& Aljumaily, 2014).

1.1 Statement of the problem

Pre-school children are still at the preoperational stage, which extends from 2-7 years, according to the intellectual development stages as identified by Piaget. This phase is characterized by shifting the quality of thinking from direct sensor experience to the ability of memory to retain the mental image and the ability to devise primary rules 
(Salameh, 2004). It is therefore advisable to focus on educating children through practical sensory experiences and activities such as instructional electronic games because their thinking at this stage is one-way, and it is difficult for them to understand the relationships between things (Alnashef, 2007).

As learning geometry concepts requires a high level of mental ability that learners should have in order to be able to absorb, analyze and understand the relationships between them. Thus, if we look at geometry teaching, we find that the main focus is on providing learners with concepts in a non-functional way, which leads to memorization them, turning them into disjointed concepts that are difficult for the learner to understand and retain. Therefore, a good teaching methodology must be chosen to provide these concepts in a functional way (Jacobson \& Lehrer, 2000). Thus, the study examines the following null hypothesis:

There are no significant statistical differences at $\alpha \leq 0.05$ between the means of prelpost geometry achievement test of the experimental/control groups due to the use of instructional electronic games on kindergarten children acquisition of geometry concepts.

\subsection{Purpose of the study}

1. Identify the geometry concepts that kindergarten children are supposed to acquire using instructional electronic games.

2. Design the environment that efficient to use instructional electronic games that can be used.

3. Identify the effectiveness of using instructional electronic games in providing children with geometry concepts.

\subsection{Significance of the study}

The importance of this study lays in the use of the constructivism theory concepts in teaching kindergarten children the different concepts, especially developing geometry concepts. The study can also help kindergarten teachers to create new instructional electronic games that motivate children to learn new concepts. Curricula designers and supervisors may also benefit from this study to develop a guidebook of instructional electronic games suitable for kindergarten children.

\section{Literature review}

2.1 Instructional electronic games

Perhaps the most important areas in which the computer has impacted significantly are electronic games. The electronic gaming industry has attracted children as a result of a number of factors, including the technical aspects of electronic games in addition to the widespread and ease of using personal computers. Its success is also attributed to its being an entertaining means that offers children the opportunity to discover and experiment without risk of responsibility or punishment.

Azmi (2014) defines electronic games as activities with an effective educational content that uses several interactive means in the light of certain criteria to achieve specific goals that the learner interacts with and provides him with feedback according to his responses. Whereas, Butler (2005) defines it as an educational activity presented in the form of a game where success may require memorizing and remembering information only or involves applying and extending this knowledge.

According to Murdan (2004), playing by computer achieves a number of goals, including: developing children's visual introspection, developing attentiveness such as focus during their narrative activities, riddles and competitions that such programs contain. It also helps to acquire self-education skill, and develops the child's ability to imagine and innovate through drawing and coloring.

Moreno (2008) and Simkova (2014) noted that there are certain conditions that must be available in electronic games, such as: adaptation, which is meant to take into account the different learning styles of students, and their different previous knowledge. Stimulations and positive response means that the educational situation in the electronic game is exciting and requires a positive response which means that the educational situation in the electronic game is exciting enough that it requires a positive response from the learner to move on to a new step. Competition where the learner encounters some solvable problems as he plays, and the competition is between the learner and the game itself, or with other students. Entertainment in that the game is meant to bring a sense of enjoyment, but taking into account the balance between pleasure and education. Feedback and immediate reinforcement is intended as the learner has responded to the stimuli so the instructional game will immediately present the results, which acts as a boost to motivate the learner to continue playing.

Zahran (2006) added to the preceding other four conditions: 1. to provide students with the opportunity to ask any questions about the game and answer them, and then determine the time of the game. 2 . To follow up the implementation of the game and sometimes intervene to remove any tension that may occur. 3 . To accurately follow feedback in order to ensure achieving objectives in a scientific and accurate way and not to fall into mistakes and misunderstandings. 4. Evaluate the instructional game, including the clarity of the instructional objectives, the steps to achieve them, and the students' reactions and impressions of the game. 
Good employment of instructional electronic games ascertains many benefits, such as increasing efficiency of teaching and learning process, assuring the quality its outputs, and applying principles of active learning. Providing learning through an unfamiliar environment may make learning more attractive and closer to the learner's emotion, prompting him to explore his imagination comfortably, thus stimulating his behavior towards learning (Asgari \& Kaufman, 2010).

\subsection{Mathematics geometry concepts:}

Learning concepts is one of the most important learning types in which children participate throughout their entire lifetime, and concept-based experiences are profound sensory experiences that are difficult to replicate or practice again after the first seven years of children's lives. In other words, they are the foundation of early childhood concepts and the basis for experiences through which subsequent experiences are interpreted.

The rapid scientific and technological development has highlighted the role that mathematics plays in this progress, so that mathematics has become the core of all sciences. Klin here states, "Mathematics is the essence of scientific theories, and some new discoveries are entirely based on mathematics which is considered as the tool to understand complicated natural phenomena" (Mansour, 2006). Aydin (2009) defined the geometric concept as the study of the images characteristics and the relationship between them, such as the relationship of parallelism, congruence, and similarity in the two dimensional space.

Concept formation consists of three stages: the stage of discrimination, in which the individual collects various schemes for certain objects and phenomena, and distinguishes between points of similarity and difference. And then comes the stage of generalization, in which the individual concludes points of similarity and difference through his observations, or comes out with a certain result or a certain understanding. And finally the stage of differentiation, in which the learner compares between what surrounds him and the standards he has constructed in his mind.

According to Jean Piaget, knowledge is a mental structure that consists of systems with an internal relationship, through which events are organized positively. Cognitive development is the change in the cognitive structures that depends on experience, and it is accomplished through two essential processes: Assimilation and Accommodation (Mohammad, 1992).

Mistaken geometry concepts, including the risk they pose to the educational process in the primary stage, hinder the learning process of those students who carry such concepts, and this will be reflected on their performance levels in their academic years. All this makes studying them and identifying their real causes an essential basis for developing curricula and choosing the teaching methods to correct them in students and avoid the formation of wrong geometric concepts in the future (Al-Harbi, et al., 2010).

Bruner has divided the stages of concept formation in children into three main stages: Enactive representation: here, concept formation based on human practical interaction with the environment. At this stage the child uses his senses to detect the characteristics and properties of tangible materials which he deals with; as he learns concepts by linking them directly to actions he performs by himself. Then comes the iconic representation stage during which the child forms his concepts by mental imagination and can represent the concepts through drawing or through semi-abstract images not related to a special work. And finally the symbolic representation stage is when the child reaches the stage of abstraction and the use of symbols, as the symbol replaces dynamic acts (Aljallad, 2004).

The child in his early stages, as stated by Cross, Wood, \& Schweingrub (2009), does not understand the meaning of the word form in all its dimensions, but he has the visual compatibility of the surrounding forms in the environment, and then he moves to the stage of having a comprehensive visual realization of the form concept without realizing its properties. And finally comes the analytical descriptive phase of the features and characteristics of the geometrical shape.

Clements (2001) supports this as he believes that teaching the child mathematics concepts at the pre-school stage helps him interact and increases his mathematical experience by playing, describing and thinking about the surrounding world. Khaleel (2009) also stressed that children should be able to recognize the geometry principles (such as identifying shapes by their names and drawing them, distinguishing between two- and three-dimensional shapes, and comparing between all shapes) during pre-school years. Hence, geometry for them is more than just naming shapes; it is an understanding of the shapes characteristics.

\subsection{Characteristics of mathematical concepts:}

Mustafa (2014) believes that the concept is not just a set of associative relationships formed by memory, nor a mere mental habit; it is a composite work that cannot be learned through training but can be achieved only when the child's mental development reaches the desired level. There are some characteristics that characterize the concept and give a clear indication of the nature of the concept and the way it grows in children's minds. Some of these characteristics are: concepts grow and develop constantly, their difficulty changes according to the stage, they are the essential tools of thought, as they grow science also develops, they are also generated by experience 
without which they will be incomplete. Moreover, the meaning of concepts varies from one person to another because of the different level of experience. Finally, concepts depend on the previous experiences of the child.

\subsection{Related studies}

The results of many studies conducted in the field of education have shown the effectiveness of instructional electronic games in the development of various concepts (practical, mathematical) in pre-school first grades children as indicated in the study of Mohammad and Obaidat (2010). The study recommended that instructional electronic games should be employed in teaching mathematics for primary grades, males and females. Also the study of Otiefy \& Elmligy (2014) showed that the use of instructional electronic games has led to the development of creative thinking skills (fluency, flexibility, originality, imagination) in children, and its great impact has given an indication of the effectiveness of using them in this field. And Soliman (2016) study indicated the effectiveness of the using instructional computer games in the development of mathematical concepts and systemic thinking among sixth graders. Whereas, the study of Al-Zeer (2017) and Alshalhoub (2011) showed the importance of developing geometric concepts among kindergarten children through the use of different strategies such as the use of a proposed program to develop spatial sense as well as mental maps.

\section{Method}

3.1 Population and sample

The study population consists of all kindergarten students at the Pink Bird Nursery in Petra city. The study was applied to a sample of 60 children, disrupted into two groups: experimental group consisting of 30 children who were taught using an instructional electronic game, and control groups consisting 30 children who were taught in the traditional way; according to the following design:

G1: O1 X O1

$\mathrm{G} 2: \mathrm{O} 1-\mathrm{O} 1$

That:

G1: The experimental group consisting of (30) kindergarten students.

O1: The achievement test in geometric concepts.

$\mathrm{X}$ : Experimental group members are taught using instructional electronic games.

G2: The control group consisting of (30) kindergarten students.

- The members of the control group are taught the traditional methodology.

\subsection{Measurement Tools:}

The study used electronic learning software from the website (https://www.splashmath.com/geometry-games) which included the programs listed in the following table:

Table 1. Instructional electronic games

\begin{tabular}{|l|l|l|l|}
\hline Game title & Objectives & Screenshots \\
\hline $\begin{array}{l}\text { Identify Two } \\
\text { Dimensional } \\
\text { shapes }\end{array}$ & $\begin{array}{l}\text { Recognize and name rectangles, } \\
\text { squares, circles and triangles } \\
\text { presented in various sizes, colors } \\
\text { and orientations }\end{array}$ & & \\
\hline $\begin{array}{l}\text { Sides and } \\
\text { Corners }\end{array}$ & $\begin{array}{l}\text { Des the picture show a square? } \\
\text { attributes of shapes like sides } \\
\text { and corners. Count the number } \\
\text { of sides and corners in various } \\
\text { shapes }\end{array}$ & & \\
\hline
\end{tabular}




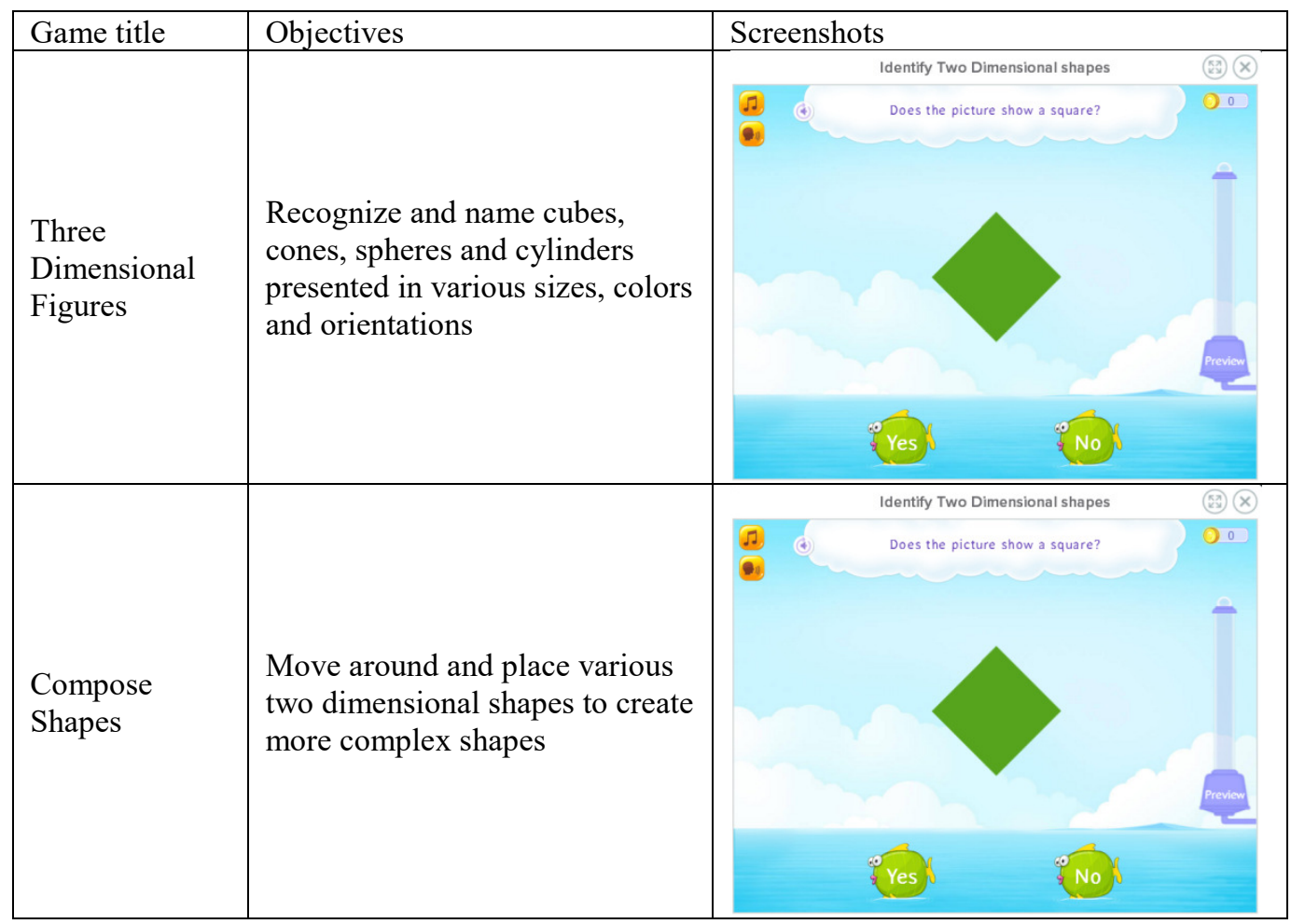

The validity of the electronic software was extracted through content analyzes and then presented to a group of referees of the university professors to determine its suitability to achieve the objectives that include the geometric concepts of kindergarten children. The test paragraphs were modified in light of the arbitrators' observations, with an average of $(80 \%)$.

Examining the geometric concepts: The study used the illustrated test of geometric concepts prepared by the researchers, which consisted of (20) paragraphs to measure geometric concepts. Reliability: Spearman - Brown Coefficient was used to calculate reliability of the measurement tool for the study, where the coefficient $=0.67$, while Guttmann split-Half coefficient $=0.66$, which indicates an acceptable value for the purposes of this study.

\section{Findings and discussion}

The data collected in this study were analyzed qualitatively to test the null hypotheses, where means and standard deviations were calculated as shown in the following table:

\begin{tabular}{llllll} 
Table 1: Means and Sd for experimental and control groups \\
\hline Groups & $\mathrm{N}$ & $\begin{array}{l}\text { Pre test } \\
\text { Mean }\end{array}$ & SD & $\begin{array}{l}\text { Post test } \\
\text { Mean }\end{array}$ & SD \\
\hline Experimental & 30 & 8.63 & 1.90 & 17.90 & 1.54 \\
Control & 30 & 3.97 & 1.96 & 9.90 & 2.07 \\
\hline Total & 60 & 6.30 & 3.03 & 13.90 & 4.42 \\
\hline
\end{tabular}

It appears according to Table 1 that there is an observed difference between the means of Experimental and control groups on the prelpost test of Geometry test. To examine the observed differences, ANCOVA and Eta Squared tests were preceded as shown in Table 2:

Table 2: ANCOVA and Eta Squared results

\begin{tabular}{lllllll}
\hline Source & Sum of Squares & df & Mean Square & F & Sig & Eta Squared \\
& & & & & & \\
\hline Pre test & 16.230 & 1 & 16.230 & 5.222 & 0.026 & \\
Group & 514.010 & 1 & 514.010 & 165.370 & $0.000(\mathrm{a})$ & 0.744 \\
Error & 177.170 & 57 & 3.108 & & & \\
\hline Total & 707.410 & 59 & & & & \\
\hline
\end{tabular}

ANCOVA revealed significant statistical differences at $(\alpha \leq 0.05)$ for the benefit of the experimental group with (a mean=17.90, sd=1.54), thus Null Hypotheses can be rejected and Alternative hypotheses can be accepted:

There are significant statistical differences at $\alpha \leq 0.05$ between the means of prelpost geometry achievement test of the experimental control groups due to the use of instructional electronic games on kindergarten children acquisition of geometry concepts.

Whereas, effect size calculated by Eta Squared $=0.744$, which means that $(744 \%)$ of the change in the 
dependent variable (Acquisition of geometry concepts) due to the Instructional Electronic Game.

This result can be explained by the fact that electronic games have the capacity to stimulate students' motivation towards learning through audio, visual and motor means provided by these games, which helps the child to engage more than one sense in understanding the geometric concepts and as a result form the correct mental image of these concepts and get rid of abstract information acquired through the traditional method. The supremacy of electronic games over the traditional methodology is attributed to its ability to create a joyful and interesting atmosphere among children, which increased their enthusiasm and led to a positive influence in acquiring and developing geometric concepts. The theory of brain-based learning is supported by challenge and stopped by threat, so this type of play provides such an environment. (AlSalti, 2004).

The educational material was presented in an interesting and attractive way where images, sound effects and movements interfered, making the child active and interactive. The supremacy is also due to the immediate feedback provided by electronic games at every response the student made, which encouraged him to challenge himself more, and continue playing to achieve the desired goal.

This finding goes in line with the findings of Al Mubireek (2003) that such games illustrate the interaction of systems as a whole, organize and integrate complex skills and show how individual actions affect systems as a whole. It is also consistent with the results of other studies like (Mohammad, Obaidat, 2010) and (Otiefy \& Elmligy, 2014).

\section{Conclusion and recommendations}

The study revealed the effectiveness of using instructional electronic games in developing geometry concepts among kindergarten children. It can be concluded that even kindergarten children can take benefits from using electronic games. In light of the study findings, the researchers recommend: Activating the method of teaching using instructional electronic games in kindergarten stage, Holding training sessions for kindergarten teachers to teach them how to use instructional electronic games, and Designing new computer educational games compatible with the developmental characteristics of kindergarten children and suitable for all school subjects.

\section{References}

Al-Harbi, Talal\& Al-Bazz, Adel\& Al-Khateeb Mohammad. (2010). Elementary Students' Mistakes in Learning Geometric Concepts and their Teachers' Level of Awareness of These Concepts. Journal of Tibah Universty, Volume (5) No. (2), 165-215.

Aljallad, Majed. (2004). Teaching Islamic education, theoretical foundations and scientific methods. Dar Almassira. Amman, Jordan.

Al-Mubireek, Khalid. (2003). Gender - oriented vs. genderneutral computer games in education.Dissertation. The Ohio State University.

Al-Nashef, Huda. (2007). Kindergarten. Dar Alfeker. Cairo, Egypt.

Al-Salti. Nadia. (2004). Brain-Based Learning. Dar Almassira. Amman, Jordan.

AL-shalhoub, Samar. (2011). Effectiveness of proposed program of the development of spatial sense and some Geometry concepts for children of the kindergarten". journal of the College of Education University of AlAzhar. (145), (1), 433-475.

Al-taee, Abtihal\& Aljumaily, Hashim. (2014).Effect of using specimen (Gerlak\& Ely)to acquire and retain mathematical concepts of the second grade female students, Journal of University of Babylon , (22), (5), 11901209.

Al-Zeer, Aisha. (2017). Effectiveness of Using Mind Map in Developing Geometry Concepts for Kindergarten Children. Journal of ALAM Altarbiah, 18(58). 1-34.

Asgari, M. \& Kaufman D. (2010). Does Fantasy Enhance Learning in Digital Games? New York: Information Science Reference.

Azmi, Nabel. (2014). Interactive learning environments. Dar Alfker. Cairo, Egypt.

Aydin, A. (2009). Prepared Map and Concept Mind Technologically-Supported, the Subjects of the Unit Social and- Systems in our Body by Students. Journal of Behavioral Sciences. 1 (1), 28-42.

Butler, D. (2005).Computer Assisted Instruction, 2nd, free Press, New York.

Clements, D. (2001) Mathematics in the preschool. Teaching Children Mathematics, 3,270-274.

Cross, T. Woods, A. \& Schweingruber, H. (2009) Mathematics Learning in early Childhood: Paths toward excellence and equity. Washington: The National Academies Press.

Dempsey, J. V., Haynes, L. L., Lucassen, B. A., Casey, M. S. (2002). Forty simple computer games and what they could mean to educators. Simulation \& Gaming, 33(2), 157-168.

Hamada, Fayza. (2005). The effectiveness of using structural model Wheatley average skill in the development of problem-solving and creative thinking in mathematics at the primary school students. Journal of the Faculty of Education, University of Assiut, vol 21, p 1, pp 405-444.

Jouda, Mousa. (2007).The Effect of the Enrichment of Some Mathematical Concepts by the Islamic Thought on 
the Scholastic Acquirement of the Students of the Tenth Grade in Gaza in Mathematics and Their Attitudes Towards it. (Unpublished M.A), The Islamic University- Gaza.

July, R. A. (2001). Thinking in three dimensions: Exploring students' geometric thinking and spatial ability with Geometer's Sketchpad. DAIA, Florida International university.

Mansour, Moin. (2006). The Effectiveness of computerized programme In Developing The Skills Of Geometrical Converts For Grade Ten In Gaza. (Unpublished M.A), The Islamic University- Gaza.

Khaleel, Aza. (2009). Mathematical Scientific Concepts and Skills in early childhood. Dar Alfker. Cairo, Egypt. Mohammad, Adel. (1992). Mental development of the child. Aldar Alsharqia, Egypt.

Mohammad, Jbreen \& obaidat, Luai. (2010). The effect of using computerized instructional games on the third graders achievement of some mathematical concepts in the first educational directorate of Irbid. Damascus University Journal for Educational Sciences. (26), (1+2), 643-672.

Moreno-Ger, P., Burgos, D., Sierra, J., and Fernandez, Manjon, B. ( 2008). Educational game design for online education, computers in Human Behavior. 24(6), 2530-2540. Doi: 10.1016/jchb.2008.03.012.

Murdan, Najem Aldeen (2004). The psychology of early childhood play. Al Falah Library, Kuwait.

Mustafa, Mansour. (2014). the importance of learning scientific concepts, Journal of social studies and researches, Univ- eloudi, Algeria, (8), 88-108.

Otiefy, Zainab \& Elmligy, Reham. (2014). The Effectiveness of use of educational electronic games to offer Geometric concepts for preschool children in developing their creative thinking skills, Journal of Childhood ,Cairo University,(17).

Pesso, Marcos Clayton. (2002). Computer in Education-Internet Projects, retrieved 22/10/2010, 10:30 from http://www.ascilite.org.au/asetarchives/confs/2002/pessoa.html

Salameh, Adel (2004). Teaching Methods of Developing concepts and scientific skills. Dar Alfker. Cairo, Egypt

Shahrori, Maha \& Rimawi, Mohamed. (2011). The Effect of Electronic Games on Memorizing, Broblem Solving and Decision Making among Middle Childhood Children. Dirasat: Educational Science, University of Jordan, (38), (2), 637-649.

Simkova, M. (2014). Using Of Computer Games In Supporting Education. Social and Behavioral Sciences, 141, 1224-1227.

Soliman, Samah. (2016). The Effectiveness of Using the Educational Computer Games on Developing Mathematical Concepts and Systemic Thinking for Sixth-Grade Students. Journal of Arab studies in education and Psychology. (77), 297-344.

Zahran, Hamed. (2006). Childhood and adolescent developmental psychology. Dar Alam Alkotoob.Cairo, Egypt. 